\title{
Convective heat transfer characteristics of China RP-3 aviation kerosene at supercritical pressure
}

\author{
Xunfeng Li ${ }^{a}$, Xiulan Huai ${ }^{a}{ }^{*}$, Jun Cai ${ }^{a}$, Fengquan Zhong ${ }^{b}$, Xuejun Fan ${ }^{b}$, Zhixiong Guo ${ }^{c}$ \\ a Institute of Engineering Thermophysics, Chinese Academy of Sciences, Beijing 100190, China \\ ${ }^{\mathrm{b}}$ Institute of Mechanics, Chinese Academy of Sciences, Beijing 100190, China \\ ${ }^{\mathrm{c}}$ Department of Mechanical and Aerospace Engineering, Rutgers, the State University of New Jersey, 98 Brett Road, Piscataway, NJ 08854, USA
}

\section{A R T I C L E I N F O}

\section{Article history:}

Received 14 February 2011

Accepted 31 March 2011

Available online 15 April 2011

\section{Keywords:}

Supercritical pressure

Aviation kerosene

Convective heat transfer

Numerical study

\begin{abstract}
A B S T R A C T
Regenerative cooling of aviation kerosene plays an important role for thermal protection of scramjet engines. Since the thermophysical properties of kerosene change acutely near the pseudo-critical point, heat convective in kerosene pipe flow is complicated. Here the convective heat transfer characteristics of China RP-3 aviation kerosene at a supercritical pressure are numerically studied using the finite volume method. The RNG $k-\epsilon$ two-equation turbulence model with enhanced wall treatment is considered. The heat transfer with different constant wall heat fluxes is analyzed, and a correlation of heat transfer enhancement is obtained. The effect of mass flow rate on the convective heat transfer with a varying wall heat flux condition at the supercritical pressure is also investigated. Because of the special thermophysical properties of the kerosene at supercritical pressure, the Nussult number is only related to the Reynolds number after the heat transfer is enhanced. The simulation results are compared with the empirical formulas in the literature.
\end{abstract}

(c) 2011 Elsevier Ltd. All rights reserved.

\section{Introduction}

The regenerative cooling of hydrocarbon fuels is one of the effective thermal protection methods for scramjet engines as generally acknowledged [1,2]. Aviation kerosene is a hydrocarbon fuel for scramjet engines; and it acts as a coolant and absorbs the heat of the engines before it is injected into the combustion chamber. The working pressure of the aviation kerosene generally exceeds its critical pressure, above which no phase transition will occur. The state of an aviation kerosene changes from liquid state to supercritical state at the supercritical pressure with the increase of temperature, and then steps into thermal cracking state with further increase of temperature [3]. The specific heat capacity of supercritical fluid has a peak value when it varies with temperature at a supercritical pressure. The temperature corresponding to the peak point is called pseudo-critical temperature at that supercritical pressure. It is well known that the thermophysical properties of fluid under supercritical pressure can change acutely when its temperature is close to the pseudo-critical temperature [4], which induces a non-conventional heat transfer. Thus, the convective heat transfer of the aviation kerosene at supercritical pressure differs from that of a fluid at a normal pressure.

\footnotetext{
* Corresponding author. Tel./fax: +86 1082543108

E-mail address: hxl@mail.etp.ac.cn (X. Huai).
}

At present most studies about the heat transfer of supercritical fluids are mainly aimed at the cooling of nuclear reactors; and the coolant working at supercritical pressure is often a simple substance, such as water $[5,6]$ or carbon dioxide $[7,8]$. Few investigations on the convective heat transfer of aviation kerosene at supercritical pressure have been reported in the literature. Hu et al. [9] experimentally studied the heat transfer of hydrofining aviation kerosene at supercritical pressure; and showed that the heat transfer enhancement occurred when the wall temperature was above the pseudo-critical temperature. They presented two correlations of heat transfer for different states at supercritical pressure. Linne et al. [10] experimentally investigated the heat transfer and thermal cracking of JP-7 aviation kerosene flowing inside different metal pipes at supercritical pressure. Their experimental results were compared with the conventional formulas of Dittus-Boelter [11] and Sieder-Tate [12]. Zhong et al. [13] inspected the fluid flow and heat transfer of China RP-3 aviation kerosene at supercritical pressure; and showed that the heat transfer was strengthened greatly when the inner wall temperature was over $600 \mathrm{~K}$. Li et al. [14] numerically studied the flow and heat transfer of China RP-3 aviation kerosene at supercritical pressure under the effect of body force. All the above-mentioned researches showed that the complicated thermophysical properties of aviation kerosene at supercritical pressure caused a non-common convective heat transfer, and the heat transfer enhancement occurred when the 


\begin{tabular}{|c|c|c|c|}
\hline \multicolumn{2}{|c|}{ Nomenclature } & $T$ & temperature, $\mathrm{K}$ \\
\hline$C_{P}$ & specific heat capacity, $\mathrm{J} /(\mathrm{kg} \cdot \mathrm{K})$ & $y$ & distance to the nearest wall, $m$ \\
\hline$d$ & inner diameter of the pipe, $\mathrm{m}$ & $y^{+}$ & near-wall characteristic number, $y^{+}=y \sqrt{\tau_{w} / \rho} / \nu$ \\
\hline G & mass flow rate, $\mathrm{kg} /\left(\mathrm{m}^{2} \cdot \mathrm{s}\right)$ & & \\
\hline$h$ & heat transfer coefficient, $\mathrm{W} /\left(\mathrm{m}^{2} \cdot \mathrm{K}\right)$ & \multicolumn{2}{|c|}{ Greek symbols } \\
\hline$k$ & turbulent kinetic energy, $\mathrm{m}^{2} / \mathrm{s}^{2}$ & $\mu$ & viscosity, $\mathrm{Pa} \cdot \mathrm{s}$ \\
\hline$K$ & thermal conductivity, $\mathrm{W} /(\mathrm{m} \cdot \mathrm{K})$ & $\nu$ & kinematic viscosity, $\mathrm{m}^{2} / \mathrm{s}$ \\
\hline$L$ & length of the pipe, $\mathrm{m}$ & $\rho$ & density, $\mathrm{kg} / \mathrm{m}^{3}$ \\
\hline $\mathrm{Nu}$ & Nusselt number, $\mathrm{Nu}=h d / K$ & $\tau_{w}$ & wall shear stress, $\mathrm{N} / \mathrm{m}^{2}$ \\
\hline$P$ & pressure, $\mathrm{Pa}$ & & \\
\hline $\operatorname{Pr}$ & Prandtl number, $\operatorname{Pr}=\mu C_{P} / K$ & \multicolumn{2}{|c|}{ Subscripts } \\
\hline$q$ & heat flux, $\mathrm{W} / \mathrm{m}^{2}$ & $b$ & bulk quantity \\
\hline $\operatorname{Re}$ & Reynolds number, $\operatorname{Re}=W d / \nu$ & $f$ & fluid \\
\hline & wall-distance-based turbulent Reynolds number, & $m$ & pseudo-critical point \\
\hline & $\operatorname{Re}_{y}=\rho y \sqrt{k} / \mu$ & $w$ & wall \\
\hline
\end{tabular}

wall temperature was near the pseudo-critical temperature. All these studies included the effect of buoyancy on the heat transfer.

In order to scrutinize the basic characteristics of the convective heat transfer without the buoyant effect for the aviation kerosene under supercritical pressure, computational fluid dynamics software FLUENT6.3 is used to simulate the flow and heat transfer of the China RP-3 aviation kerosene at a supercritical pressure in this paper. The RNG $k-\epsilon$ two-equation turbulence model with enhanced wall treatment is applied in this simulation. A ten-species surrogate [13] is used for predicting the approximate thermophysical and transport properties of the China RP-3 aviation kerosene.

\section{Simulation}

\subsection{Boundary conditions}

Consider the China RP-3 aviation kerosene flow inside a straight pipe. Buoyancy is excluded in order to investigate the basic characteristics of convective heat transfer of the kerosene at supercritical pressure. Since the thermal cracking of the China RP-3 aviation kerosene occurs obviously when the temperature is over
$850 \mathrm{~K}$ [15], the maximum wall temperature is restricted to below $850 \mathrm{~K}$ in this study.

The structural and boundary conditions are shown below:

(1) The inner diameter of the pipe is $0.012 \mathrm{~m}$. The length of the unheated section from the inlet is $0.5 \mathrm{~m}$, so that the flow into the heated section is fully developed. The length of the heated section is $4.5 \mathrm{~m}$.

(2) The inlet pressure is $4 \mathrm{MPa}$. The inlet temperature is $300 \mathrm{~K}$. An outflow boundary condition is applied to the outlet.

(3) The mass flow rate varies from 500 to $1100 \mathrm{~kg} /\left(\mathrm{m}^{2} \cdot \mathrm{s}\right)$.

(4) The considered range of the wall heat flux is $300-700 \mathrm{~kW} / \mathrm{m}^{2}$.

\subsection{Thermophysical properties}

The thermophysical properties of the China RP-3 aviation kerosene are calculated by the NIST Supertrapp software [16] with a ten-species surrogate [13]. The calculated critical temperature and pressure of the China RP-3 aviation kerosene are $660 \mathrm{~K}$ and 2.4 MPa, respectively. While the measured critical temperature and pressure are $646 \mathrm{~K}$ and $2.4 \mathrm{MPa}$ [17], respectively. Thus, the ten-

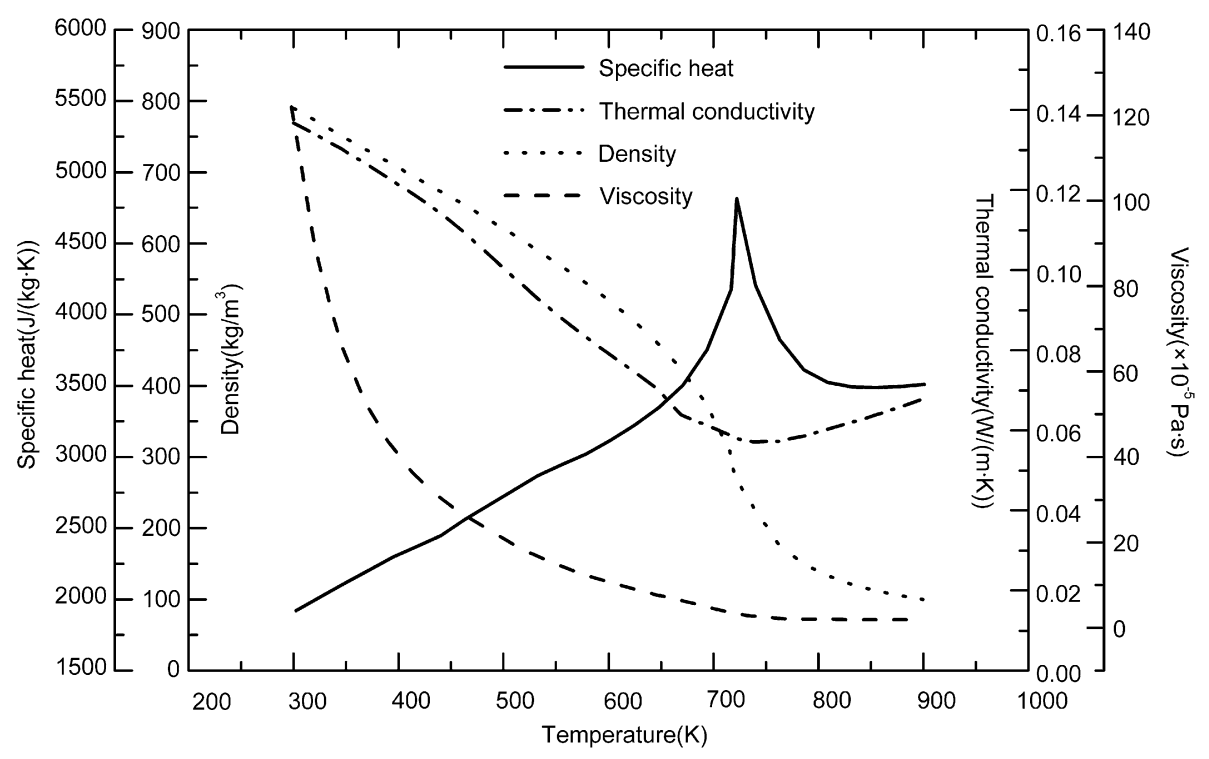

Fig. 1. Thermophysical properties of the China RP-3 aviation kerosene at a supercritical pressure of 4 MPa. 
species surrogate of the China RP-3 aviation kerosene is reliable. Fig. 1 shows the variation of the computed thermophysical properties of the China RP-3 aviation kerosene with the temperature at a supercritical pressure of $4 \mathrm{MPa}$. At this pressure, the pseudocritical temperature is $720 \mathrm{~K}$. The thermophysical properties of the aviation kerosene are different from those of water [18] at supercritical pressure because the aviation kerosene is composed of many organic compounds. So the convective heat transfer of the aviation kerosene at supercritical pressure will become more complicated.

\subsection{Numerical methods}

The pressure-based solver in FLUENT6.3 is adopted to solve the governing equations for the flow and heat transfer of the China RP-3 aviation kerosene at supercritical pressure. The convection term is handled by the second-order upwind difference scheme. The diffusion term is discretized with the second-order central difference scheme. The SIMPLEC algorithm is employed to resolve the coupling between velocity and pressure. The implicit GaussSeidel iteration is used to handle the time advancing. In order to achieve the required precision for the computational data, the distance of the wall-adjacent cell to the wall should be controlled to fit the requirement of $y^{+} \leq 1$ in the calculational domain. $y^{+}$can be derived from

$y^{+}=\frac{y}{\nu} \sqrt{\frac{\tau_{w}}{\rho}}$

where $y$ is the distance to the nearest wall, $\tau_{w}$ is the shear stress of the wall, $\nu$ is the kinematic viscosity of fluid, and $\rho$ is the density of fluid.

In the same time, there should be at least 10 cells within the viscosity-affected near-wall region to satisfy the calculational precision in that region. Those regions can be judged by $\operatorname{Re}_{y} \leq 200$. $\mathrm{Re}_{y}$ is defined as

$\operatorname{Re}_{y}=\frac{\sqrt{k} y}{\nu}$

where $k$ is the turbulent kinetic energy.

The density, specific heat capacity, thermal conductivity and viscosity of the China RP-3 aviation kerosene are all computed by the software of NIST Supertrapp [16] as a function of temperature and pressure.

\subsection{Validation of the simulation method}

The simulation method should be validated before applying it to the convective heat transfer of the China RP-3 aviation kerosene at a supercritical pressure. For there exist no good experimental data on the convective heat transfer of the China RP-3 aviation kerosene, for validation purpose, the heat transfer of water at a supercritical pressure is computed by using this numerical method. The critical pressure and temperature of water are $647 \mathrm{~K}$ and $22.1 \mathrm{MPa}$, respectively. The water flows inside an upright pipe with an inner diameter of $0.0075 \mathrm{~m}$ at a supercritical pressure of $24.5 \mathrm{MPa}$. The mass flow rate is $1260 \mathrm{~kg} /\left(\mathrm{m}^{2} \cdot \mathrm{s}\right)$. The calculated results are compared with the classical experimental data in reference [4]. Fig. 2 shows the comparisons, in which Fig. 2(a) is the change of the heat transfer coefficient with the bulk temperature, and Fig. 2(b) is the change of the wall temperature with the bulk enthalpy. The maximum difference of the wall temperature between the present prediction and the previous experimental study is less than $2 \%$. However, the precision of the heat transfer coefficient is not obtained because the uncertainty in the experimental data near the pseudo-critical temperature is large.

\section{Results and discussion}

A two-dimensional axisymmetric model is used to simulate the flow and heat transfer of the China RP-3 aviation kerosene at the supercritical pressure. The effects of grid size have been studied in advance. The radial grids are selected among 40, 50 and 60 . The axial grids are selected among 500, 1000 and 2000. The grids nearwall satisfies the requirement of Chapter 2.3. By the analysis of the heat transfer coefficient and wall temperature at different grids combination, the maximum deviation among above grids combination is within $1 \%$. Finally, the grids of $50 \times 1000$ (radial $\times$ axial) are adopted as the baseline for the calculations hereinafter.

\subsection{Constant wall heat flux}

The convective heat transfer of the China RP-3 aviation kerosene at a supercritical pressure is investigated with constant wall heat flux values of $300,400,500$ and $600 \mathrm{~kW} / \mathrm{m}^{2}$, respectively. The mass flow rate is $884 \mathrm{~kg} /\left(\mathrm{m}^{2} \cdot \mathrm{s}\right)$. Fig. 3 shows the distributions of the wall temperature under different wall heat fluxes. The difference of the wall temperatures with different wall heat fluxes is large at the initial heating section. Then the difference begins to decrease along

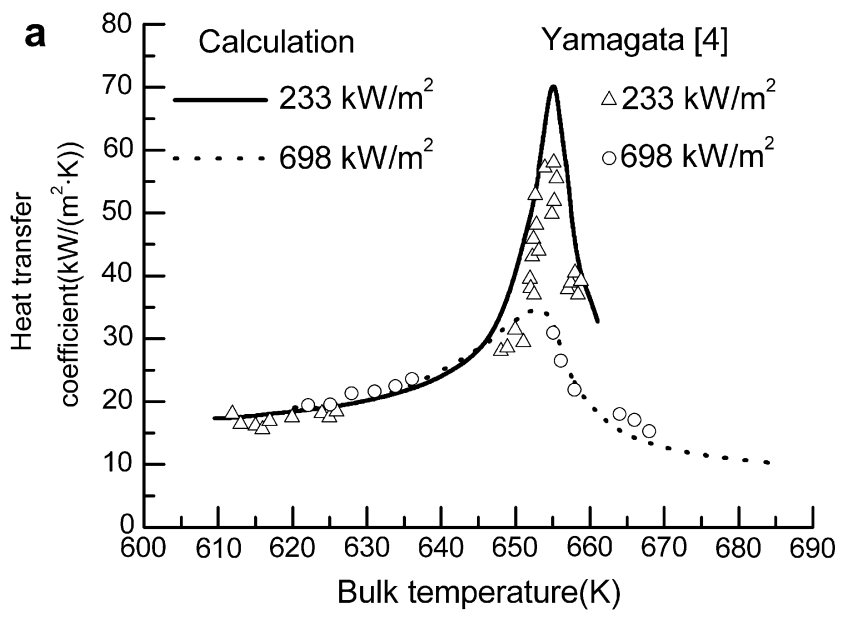

b

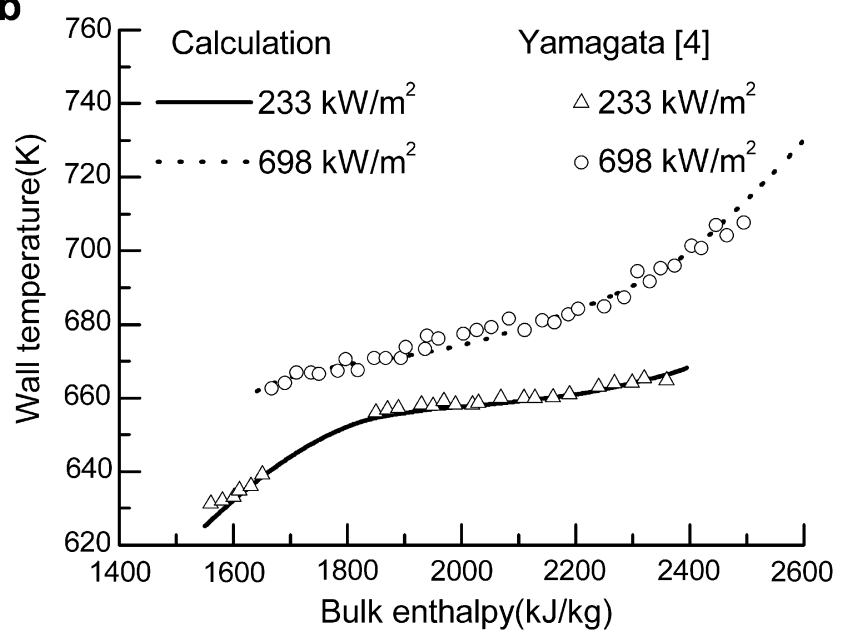

Fig. 2. Comparisons between the experimental and computational data for water at $P=24.5 \mathrm{MPa}, G=1260 \mathrm{~kg} /\left(\mathrm{m}^{2} \cdot \mathrm{s}\right)$ and $d=0.0075 \mathrm{~m}$ (a. Heat transfer coefficient b. Wall temperature). 


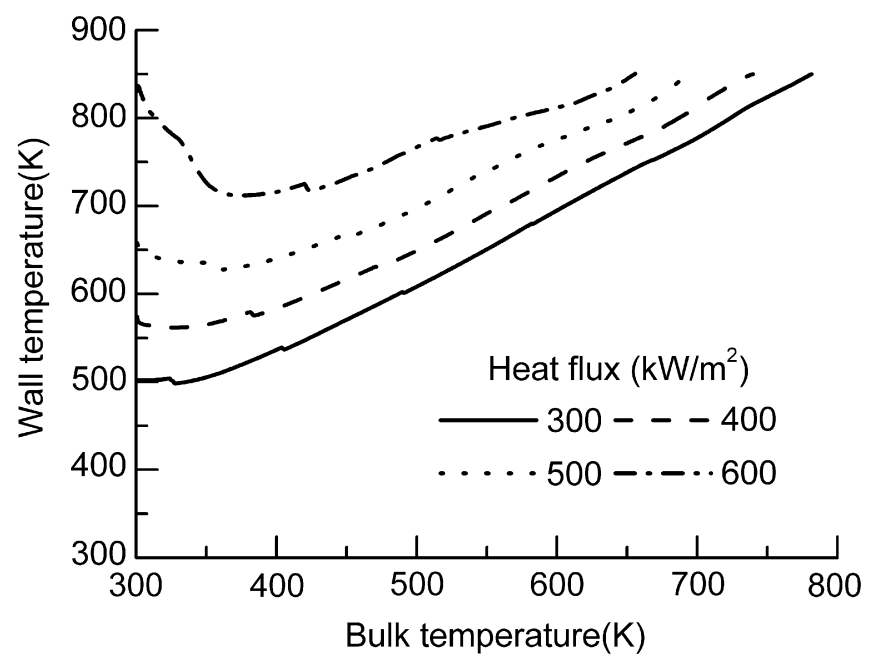

Fig. 3. Distributions of the wall temperature under different wall heat fluxes at $G=884 \mathrm{~kg} /\left(\mathrm{m}^{2} \cdot \mathrm{s}\right)$.

the flow direction. The wall temperature falls firstly and then begins to increase when the wall heat flux is greater than $400 \mathrm{~W} / \mathrm{m}^{2}$. Furthermore, the larger the wall heat flux is, the more the fluctuation of the wall temperature is. Fig. 4 shows the distributions of the heat transfer coefficient under different wall heat fluxes. The higher the wall heat flux is, the lower the heat transfer coefficient is. In general, the heat transfer coefficient rises along the flow direction. The heat transfer is enhanced when the wall temperature over the pseudocritical temperature along the flow direction.

It is seen from Fig. 3 that the wall temperature is higher than the pseudo-critical temperature at the initial heating section when the wall heat flux is greater than or equal to $600 \mathrm{~kW} / \mathrm{m}^{2}$. But, the corresponding heat transfer coefficient is lower obviously than that with the wall heat flux less than $600 \mathrm{~kW} / \mathrm{m}^{2}$. These show that the heat transfer is not improved when the wall temperature at the initial heating section is higher than the pseudo-critical temperature. On the contrary, the heat transfer is weakened. The heat transfer is relatively enhanced only when the wall temperature rises above the pseudo-critical temperature from a lower temperature.

From the principle of Newton's cooling, the wall temperature can be expressed by

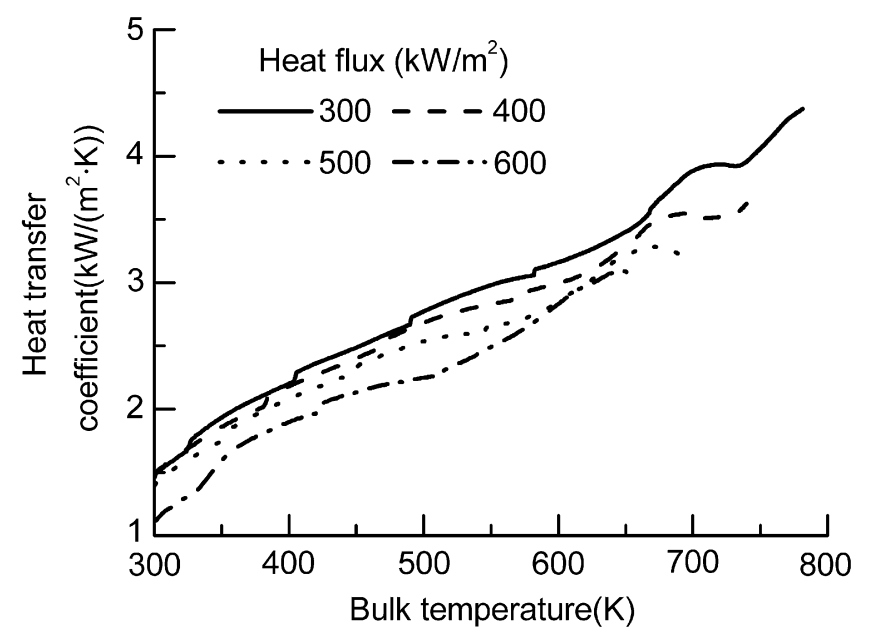

Fig. 4. Distributions of the heat transfer coefficient under different wall heat fluxes at $G=884 \mathrm{~kg} /\left(\mathrm{m}^{2} \cdot \mathrm{s}\right)$.

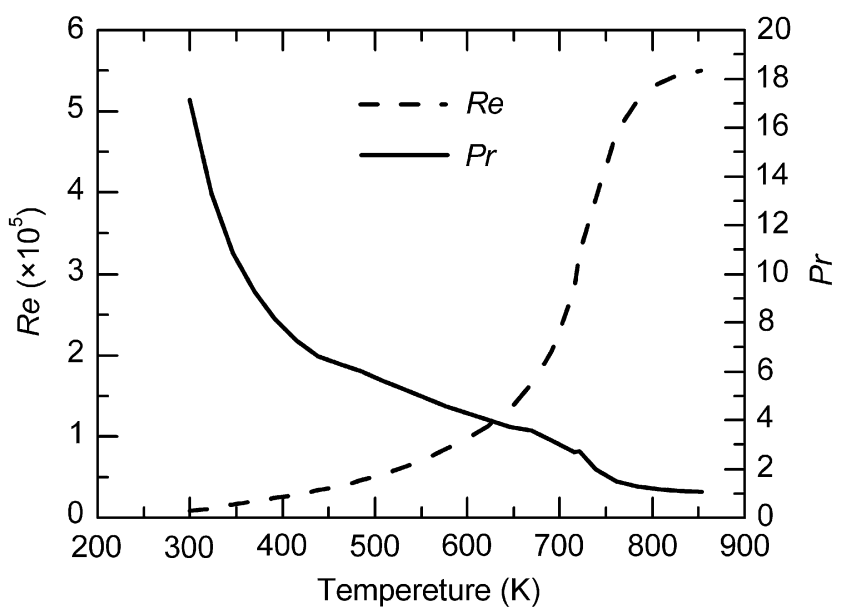

Fig. 5. Changes of Reynolds number and Prandtl number with temperature at $G=884 \mathrm{~kg} /\left(\mathrm{m}^{2} \cdot \mathrm{s}\right)$.

$T_{w}=\frac{q}{h}+T_{b}$

where $q$ is the wall heat flux, $h$ is the heat transfer coefficient, and $T_{b}$ is the bulk temperature.

The increase of heat transfer coefficient along the flow direction makes the first term on the right hand side of formula (3) decreasing. While the bulk temperature in the second term on the right hand side of formula (3) rises. So the wall temperature can increase or decrease, depending on the comprehensive effects of those two terms. The rise of the wall heat flux makes the heat transfer coefficient decreasing. Combining the formula (3), the higher the wall heat flux is, the higher the initial wall temperature is. Furthermore, the decrease of the value of $q / h$ is rapider with higher wall heat flux along the flow direction. When the decrease of the value of $q / h$ exceeds the increase of the bulk temperature, the decrease of wall temperature occurs, for example, the change of the wall temperature with the wall heat flux is $600 \mathrm{~kW} / \mathrm{m}^{2}$. Thus, the changes of the wall temperatures with different wall heat fluxes in Fig. 3 are different.

The abrupt change of the thermophysical properties of fluids at supercritical pressure induces significant changes in the heat

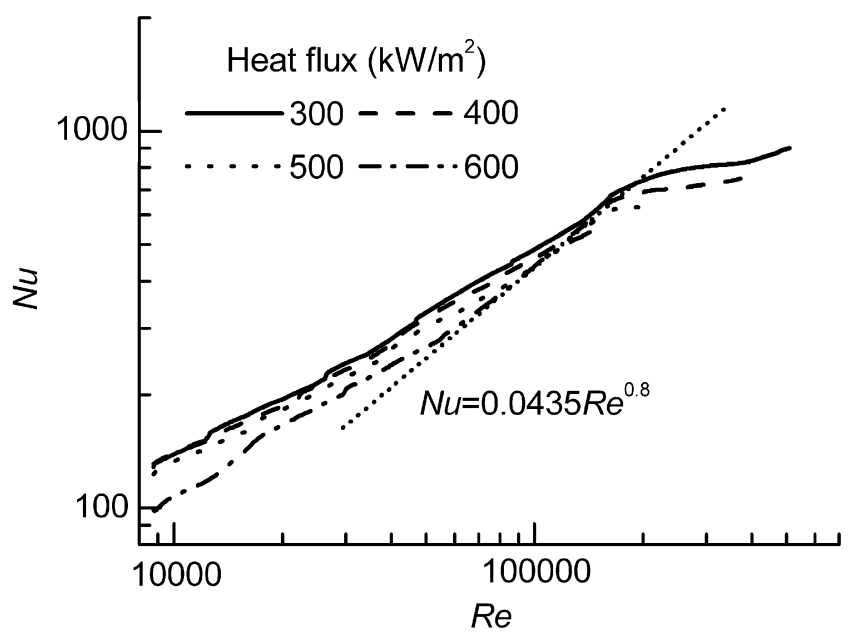

Fig. 6. Change of Nusselt number with Reynolds number for different wall heat fluxes at $G=884 \mathrm{~kg} /\left(\mathrm{m}^{2} \cdot \mathrm{s}\right)$. 


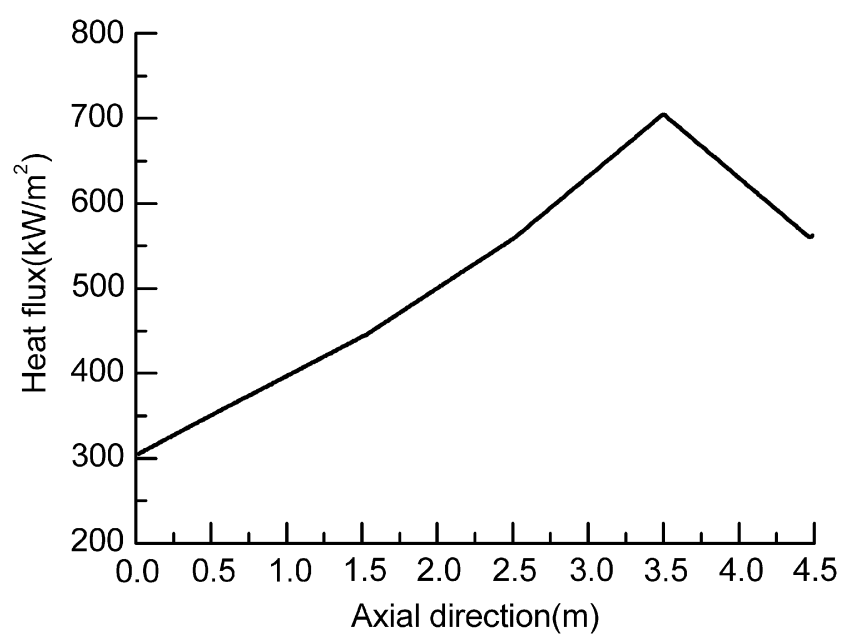

Fig. 7. Distribution of the varying wall heat flux.

transfer coefficient and Reynolds number in fluid flow and heat transfer, which is different from the normal convective heat transfer at a normal pressure. For the normal convective heat transfer there is no change in heat transfer coefficient and Reynolds number under fully-developed flow conditions. Fig. 5 shows the changes of Reynolds number and Prandtl number with temperature. The Reynolds number rises as the temperature increasing, and increases sharply nearby the pseudo-critical temperature. However, the heat transfer deterioration occurs (shown in Fig. 4) when the bulk temperature reaches the pseudo-critical temperature even if the Reynolds number increasing.

Fig. 6 shows the change of the Nusselt number with the Reynolds number with different wall heat fluxes. The changing trend of the Nusselt number is in accordance with that of the heat transfer coefficient shown in Fig. 4. A formula of the heat transfer enhancement for the China RP-3 aviation kerosene is obtained by the fitting analyses:

$\mathrm{Nu}=0.0435 \operatorname{Re}^{0.8}$

Formula (4) indicates that the Nusselt number is only related to the Reynolds number when the heat transfer of the China RP-3 aviation kerosene at supercritical pressure is enhanced. The Prandtl number decreases with the increase of temperature before

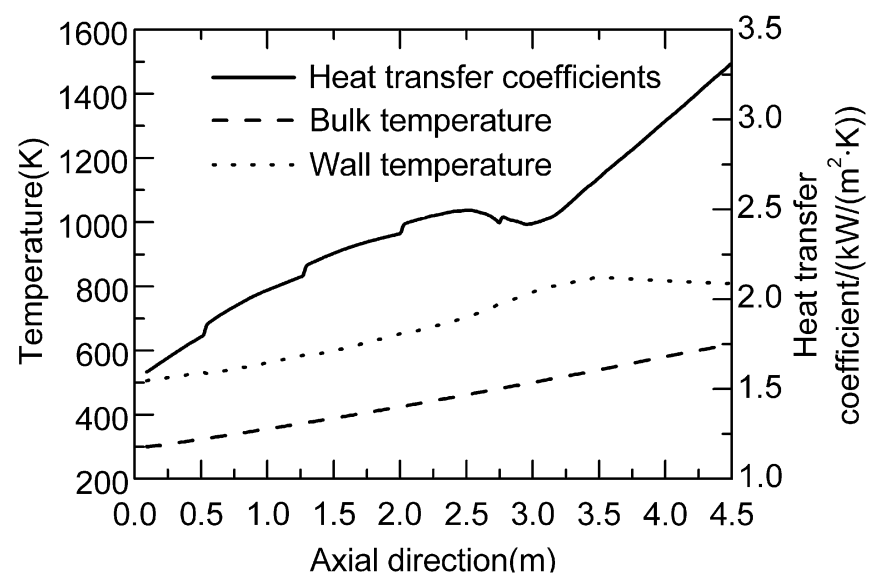

Fig. 8. Distributions of the bulk/wall temperature and heat transfer coefficient at $G=884 \mathrm{~kg} /\left(\mathrm{m}^{2} \cdot \mathrm{s}\right)$.

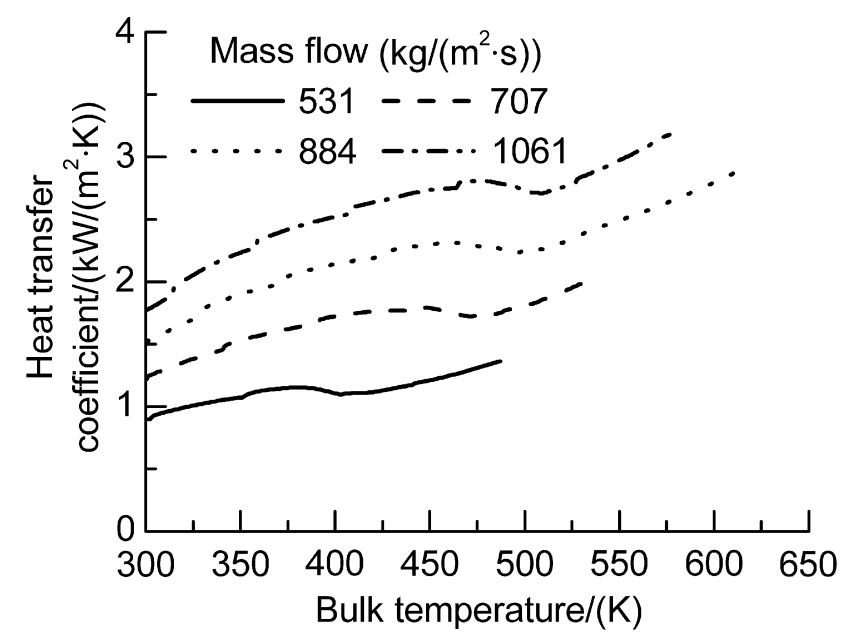

Fig. 9. Distributions of the heat transfer coefficient at different mass flow rates.

the pseudo-critical point and then changes flatly with its value approximately equal to unit after the pseudo-critical point as shown in Fig. 5. Furthermore, the change of supercritical pressure has little effect on the Prandtl number after the temperature is over the corresponding pseudo-critical temperature [19]. Thus, the effect of Prandtl number on the heat transfer of the RP-3 kerosene at supercritical pressure can be omitted after the heat transfer is enhanced. Although the Reynolds number increases rapidly when the bulk temperature is close to the pseudo-critical temperature, the relative heat transfer deterioration occurs. So the Nusselt number becomes flat after the heat transfer is enhanced.

\subsection{Varying wall heat flux}

The simulation of the heat transfer of the China RP-3 aviation kerosene with varying wall heat flux is carried out. Fig. 7 shows the distribution of the varying wall heat flux, which refers to the true distribution of the wall heat flux of scramjet in reference [20]. The distributions of the bulk temperature, wall temperature and heat transfer coefficient at the mass flow rate of $884 \mathrm{~kg} /\left(\mathrm{m}^{2} \cdot \mathrm{s}\right)$ are shown in Fig. 8. Although the rise of the bulk temperature along the flow direction increases the Reynolds number, the heat transfer coefficient turns down when the wall temperature is close to the

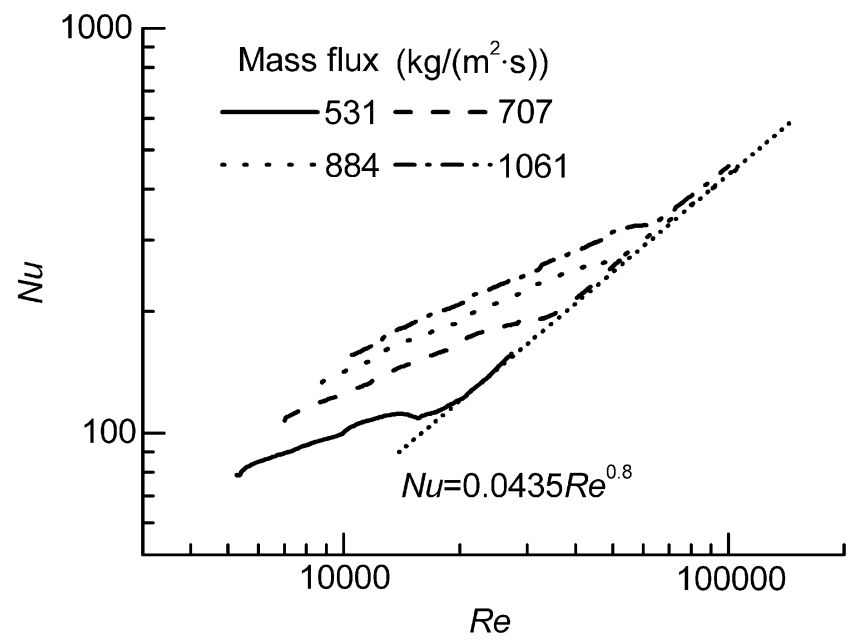

Fig. 10. Change of the Nusselt number with Reynolds number at different mass flow. 
Table 1

Empirical formulas of heat transfer for aviation kerosene at supercritical pressure.

\begin{tabular}{|c|c|c|}
\hline Kerosene type & Common heat transfer & Supercritical heat transfer \\
\hline $\begin{array}{l}\text { Hydrofining } \\
\text { kerosene [9] }\end{array}$ & $\mathrm{Nu}_{0}=0.008 \mathrm{Re}^{0.873} \mathrm{Pr}^{0.451}$ & $\mathrm{Nu} / \mathrm{Nu}_{0}=1+1.67 \frac{\left(t_{w 0}-t_{m}\right)}{t_{m}}$ \\
\hline RP-3 [13] & $\mathrm{Nu}=0.0065 \operatorname{Re}^{0.89} \operatorname{Pr}^{0.4}\left(\frac{\mu_{f}}{\mu_{w}}\right)^{0.1}$ & $\mathrm{Nu}=0.000045 \operatorname{Re}^{1.4} \operatorname{Pr}^{0.4}\left(\frac{\mu_{f}}{\mu_{w}}\right)^{0 .}$ \\
\hline JP-7 [21] & $\mathrm{Nu}=0.01 \operatorname{Re}^{0.906} \operatorname{Pr}^{0.4}$ & - \\
\hline RP-3 (Present) & - & $\mathrm{Nu}=0.0435 \mathrm{Re}^{0.8}$ \\
\hline
\end{tabular}

pseudo-critical temperature. That resembles the change of the heat transfer coefficient near the pseudo-critical temperature occurred in Fig. 4, where the heat transfer coefficient does not turn down, and only the rise of the heat transfer coefficient slows down. The heat transfer coefficient begins to rise rapidly when the wall temperature is over the pseudo-critical temperature under the condition of the varying wall heat flux, which indicates that the heat transfer is enhanced. However, the wall temperature begins to decrease slowly corresponding to the drop of the wall heat flux. The wall temperature changes from lower temperature to higher temperature over the pseudo-critical temperature along the flow direction, and the bulk temperature is always lower than the pseudo-critical temperature.

Fig. 9 is the distributions of the heat transfer coefficient at different mass flow rates. Fig. 10 is the change of the Nusselt number with the Reynolds number at different mass flow rates. The greater the mass flow rate is, the greater the heat transfer coefficient is. The heat transfer coefficient decreases firstly when the wall temperature is close to the pseudo-critical temperature, which indicates that the relative heat transfer deterioration occurs. And then rises rapidly when the wall temperature is over that temperature, corresponding to the heat transfer enhancement. However, the decrease of the mass flow rate causes the heat transfer enhancement ahead. Furthermore, the Nusselt number accords well with formula (4) after the heat transfer is enhanced. Those support the findings in Subsection 3.1, i.e., the Nusselt number is only related to the Reynolds number and the other parameters can be neglected after the heat transfer of the China RP-3 aviation kerosene at supercritical pressure is enhanced.

\subsection{Comparison with empirical formulas}

Some researchers have carried out experimental studies about the heat transfer of aviation kerosene at supercritical pressure, and obtained some empirical formulas. Table 1 shows several empirical formulas of heat transfer for aviation kerosene at supercritical pressure. The heat transfer of aviation kerosene at supercritical pressure is divided into a common heat transfer by the wall temperature being lower than its pseudo-critical temperature and a supercritical heat transfer by the wall temperature being higher than its pseudo-critical temperature.

The critical pressure of the hydrofining aviation kerosene in reference [9] is $2.459 \mathrm{MPa}$, and its critical temperature is $677.5 \mathrm{~K}$. The critical values are close to those of the China RP-3 aviation kerosene. $t_{m}$ in the empirical formula corresponding to the supercritical heat transfer in reference [9] was the pseudo-critical temperature. $t_{w 0}$ was the wall temperature, which was computed by $\mathrm{Nu}_{0}$ of the common heat transfer with the same heat flux and bulk temperature.

The Dittus-Boelter formula and Sieder-Tate formula are the classical heat transfer formulas at normal conditions with temperature difference correction, which are described by

$$
\text { Dittus - Boelter formula } \mathrm{Nu}=0.023 \operatorname{Re}^{0.8} \operatorname{Pr}^{0.4}\left(\frac{\mu_{f}}{\mu_{w}}\right)^{0.11}
$$

Sieder - Tate formula $\mathrm{Nu}=0.027 \operatorname{Re}^{0.8} \operatorname{Pr}^{0.333}\left(\frac{\mu_{f}}{\mu_{w}}\right)^{0.14}$

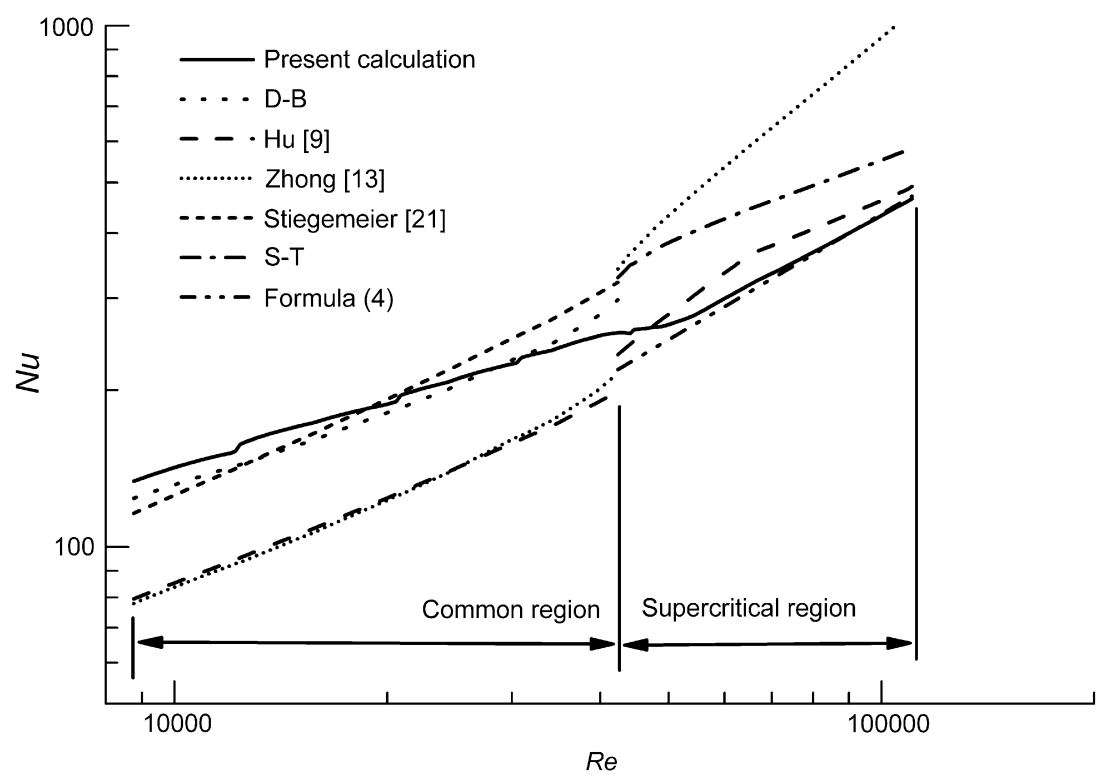

Fig. 11. Comparisons between the present calculations and the empirical formulas with varying wall heat flux at $G=884 \mathrm{~kg} /\left(\mathrm{m}^{2} \cdot \mathrm{s}\right)$. 
Linne et al. [10] compared the heat transfer of JP-7 aviation kerosene at supercritical pressure with formulas (5) and (6), showed that the convective heat transfer fitted the Dittus-Boelter formula at the starting time of heating. Then the heat transfer was enhanced after some time of heating, and the Nusslet number began to agree with the Sieder-Tate formula, even exceeded the formula at higher temperature section.

The comparisons between the present simulation result for the China RP-3 aviation kerosene at the supercritical pressure and the results computed by the empirical formulas are shown in Fig. 11. The wall heat flux is varying as shown in Fig. 7. The mass flow rate is $884 \mathrm{~kg} /\left(\mathrm{m}^{2} \cdot \mathrm{s}\right)$. The inlet pressure is $4 \mathrm{MPa}$. The calculated results are compared with the Dittus-Boelter formula, as well as the empirical formulas given by $\mathrm{Hu}$ et al. [9], Zhong et al. [13] and Stiegemeier et al. [21] at the common heat transfer region. The simulated results are close to the Dittus-Boelter formula and the empirical formula of the JP-7 obtained by Stiegemeier et al. [21]. But the changing rate of the calculated results is the least at common heat transfer region. However the empirical formulas given by $\mathrm{Hu}$ et al. [9] and Zhong et al. [13] are coincident perfectly. But their data are much lower than the present calculations. The relative enhancement of the heat transfer occurs at the supercritical heat transfer region. The computed results are slightly lower than the empirical formula by Hu et al. [9], and are far lower than the SiederTate formula and the empirical formula of the RP-3 by Zhong et al. [13]. Among them, the heat transfer enhancement of the RP-3 obtained by Zhong et al. [13] is the strongest at the supercritical heat transfer region.

Fig. 11 shows that the experimental results are also different for the supercritical kerosene because that the experimental conditions and thermophysical properties of kerosene, and so on, are different. All of their experiments were affected possibly by buoyancy. The effect of buoyancy on the heat transfer of supercritical fluid often is large [6]. However, the effect of buoyancy on the heat transfer in this paper was not considered. Those maybe cause the simulational result in this paper different from the experimental results in the literatures.

\section{Conclusions}

The RNG $k$ - $\epsilon$ two-equation turbulence model with enhanced wall treatment is adopted to study the heat transfer characteristics of the China RP-3 aviation kerosene at the supercritical pressure. The results of this study show that the large change of the thermophyscial properties of the aviation kerosene at the supercritical pressure complicates the heat transfer.

The variety of the bulk temperature and heat transfer coefficient results in the complex change of the wall temperature at different constant wall heat fluxes. The heat transfer can be augmented when the wall temperature rises over the pseudo-critical temperature from the lower temperature along the flow direction. However, the heat transfer is not enhanced, but weakened, when the wall temperature is over the pseudo-critical temperature at the initial heating section. The relative deterioration of the heat transfer occurs when the wall temperature or the bulk temperature are close to the pseudo-critical temperature.
The Nusselt number for the heat transfer of the China RP-3 aviation kerosene at the supercritical pressure is only related to the Reynolds number after the heat transfer is enhanced, and the effects of other parameters are negligible. The relation between the Nusselt number and the Reynolds number at the supercritical heat transfer region is obtained. The comparisons between the simulation result and the empirical formulas show that the results from the empirical formulas presented by different researchers are different and also different from the calculational result in this paper.

\section{Acknowledgements}

The authors gratefully acknowledge the financial support of the National Natural Science Foundation of China (No. 50906083) and the National Basic Research Program of China (No. 2011CB710705).

\section{References}

[1] Q.J. Fu, K. Yan, Z.G. Du, N. Li, Research progress of endothermic hydrocarbon fuels, J. Rocket Propulsion 31 (2005) 32-36.

[2] J. Jiang, R.L. Zhang, J.L. Le, The calculational tool of thermal structure design for regeneratively cooled scramjet, J. Exp. Fluid Mechanics 30 (2006) 1-7.

[3] X.J. Fan, G. Yu, J.G. Li, X.N. Lu, X.Y. Zhang, C.J. Sun, Combustion and ignition of thermal cracked kerosene in supersonic model combustors, J. Propul. Power 23 (2007) 317-324.

[4] K. Yamagata, K. Nishikawa, S. Hasegawa, T. Fujii, S. Yoshida, Forced convective heat transfer to supercritical water flowing in tubes, Int. J. Heat Mass Trans. 15 (1972) 2575-2593.

[5] J. Yang, Y. Oka, Y. Ishiwatari, J. Liu, J. Yoo, Numerical investigation of heat transfer in upward flows of supercritical water in circular tubes and tight fuel rod bundles, Nucl. Eng. Des. 237 (2007) 420-430.

[6] M. Bazargan, D. Fraser, V. Chatoorgan, Effect of buoyancy on heat transfer in supercritical water flow in a horizontal round tube, J. Heat Trans. ASME 127 (2005) 897-902.

[7] X.R. Zhang, H. Yamaguchi, Forced convection heat transfer of supercritical $\mathrm{CO}_{2}$ in a horizontal circular tube, J. Supercrit. Fluids 41 (2007) 412-420.

[8] X.L. Huai, S. Koyama, T.S. Zhao, An experimental study of flow and heat transfer of supercritical carbon dioxide in multi-port mini channels under cooling conditions, Chem. Eng. Sci. 60 (2005) 3337-3345.

[9] Z.H. Hu, T.K. Chen, Y.S. Luo, J.X. Zheng, M. Tang, Heat transfer characteristics of kerosene at supercritical pressure, J. Xi'an Jiaotong Univ. 33 (1999) 62-65.

[10] D.L. Linne, M.L. Meyer, T. Edwards, D.A. Eitman, Evaluation of Heat Transfer and Thermal Stability of Supercritical JP-7 Fuel (1997) AIAA-1997-3041.

[11] F.W. Dittus, L.M.K. Boelter, Heat transfer in automobile radiators of the tubular type, Int. Commun. Heat Mass 12 (1985) 3-22.

[12] E.N. Sieder, G.E. Tate, Heat transfer and pressure drop of liquid in tubes, Ind. Eng. Chem. 28 (1936) 1429-1436.

[13] F.Q. Zhong, X.J. Fan, G. Yu, J.G. Li, X.N. Lu, Heat Transfer of Aviation Kerosene at Supercritical Conditions (2008) AIAA-2008-4615.

[14] X.F. Li, F.Q. Zhong, X.J. Fan, X.L. Huai, J. Cai, Study of turbulent heat transfer of aviation kerosene flows in a curved pipe at supercritical pressure, Appl. Therm. Eng. 30 (2010) 1845-1851.

[15] X.J. Fan, G. Yu, J.G. Li, L.J. Yue, Effects of entry conditions on cracked kerosene fueled supersonic combustor performance, Combust. Sci. Technol. 179 (2007) 2199-2217.

[16] J.F. Ely, M.L. Huber, NIST Standard Reference Database 4-NIST Thermophysical Properties of Hydrocarbon Mixtures. National Inst. of Standards, Gaithersburg, MD, 1990.

[17] Q.M. Sun, Z.T. Mi, X.W. Zhang, Determination of critical properties $\left(t_{c}, p_{c}\right)$ of endothermic hydrocarbon fuels-RP-3 and simulated JP-7, J. Fuel Chem. Technol. 34 (2006) 466-470.

[18] F. Roelofs, CFD Analyses of Heat Transfer to Supercritical Water Flowing Vertically Upward in a Tube. NRG, 2004, 21353/04.60811/P.

[19] X.J. Fan, G. Yu, Analysis of thermophysical properties of Daqing RP-3 aviation kerosene, J. Propul. Technol. 27 (2006) 187-192.

[20] L.M. Zheng, B. Sun, 2D thermal environment numerical simulation of scramjets, J. Aerospace Power 22 (2007) 823-828.

[21] B. Stiegemeier, M.L. Meyer, R. Taghavi, A Thermal Stability and Heat Transfer Investigation of Five Hydrocarbon Fuels (2002) AIAA-2002-3872. 